\title{
Using Information Technology in Education to Manage a Professional Learning Community (PLC)
}

\author{
Maree A. Skillen \\ Arden Anglican School, Sydney, Australia \\ docree@bigpond.com
}

\begin{abstract}
This paper considers professional learning communities (PLC) and the role that they have in a developing secondary School in New South Wales, Australia. A brief identification and discussion of the importance of professional learning is presented, together with an examination of the effects of professional learning on teachers and subsequent classroom practice. Models and frameworks that have been utilised along with the implementation of information technology as a tool to manage the PLC are presented, and the sustainability of such structures considered. Practical examples will be used to further support and illustrate how the developing School embraced professional learning to build a culture, a discourse and a community.
\end{abstract}

Keywords: Professional Learning Community (PLC), educational management, information technology, Moodle, model, framework.

\section{Introduction}

"Collaboration is a way to generate knowledge and examine and build theories about educational practice. Ideas are challenged and ideologies and historical views of current practice are critically examined. What is taken for granted about language, culture, power and learning is critiqued".

(Hill, 1992)

As professionals, teachers must continually update, deepen, and refine their knowledge and skills through professional development (Timperley, Phillips, Wiseman and Fung, 2003, p.1). The goal of professional development should be to raise student achievement. To be judged effective, therefore, professional development must result in ongoing benefits as measured by improvements in student achievement. However, there is a growing body of research that shows that much professional development does not lead to long-term changes in teaching that improve student achievement. DuFour (2004) states that "the idea of improving schools by developing professional learning communities is currently in vogue". The term has been used broadly and ubiquitously, so that researchers believe that "... it is in danger of losing all meaning".

\section{Professional Learning Communities (PLCs)}

Gabelnick, MacGregor, Matthews, and Smith (1990) have defined professional learning communities as being opportunities to "purposefully restructure the curriculum to link 
together courses or course work so that students find greater coherence in what they are learning as well as increased intellectual interaction with faculty and fellow students". At their core, learning communities involve "co-registration or block scheduling that enables students to take courses together" (Tinto, 1998). In practice, learning communities vary in scope and services. Some provide courses linked by a common theme while others offer academic and student supports embedded in the linked courses.

\subsection{Models and Frameworks}

Figure 3 depicts a 'Professional Learning Framework' taken from CEASA (The council of Education Associations of South Australia) which has been designed to support teachers, through the activities of their professional association to plan teacher learning programs for sustainable changed pedagogy. It was developed in partnership with the "Teacher Quality" Unit within Organisation \& Professional Development Services (OPDS) of DECS. It is OPDS which oversees the contract between CEASA and DECS. The Framework is based on current research of the elements that best support sustainable professional learning. The Framework supports teachers to reflect on their knowledge, skills, practice, values and beliefs through inquiry processes. It provides a comprehensive, structured approach teacher learning and has been developed to inform the design of association CEASA funded activities in 2006.

The six elements of the 'Professional Learning Framework' call for professional learning that is collaborative, planned, focused on the classroom, based on inquiry processes, data collection and analysis and supported by quality leadership. Each of the six elements of the Framework works together to produce high quality professional learning that is sustainable. The Framework provides opportunities for educators to engage in dialogue and explore current research related to curriculum

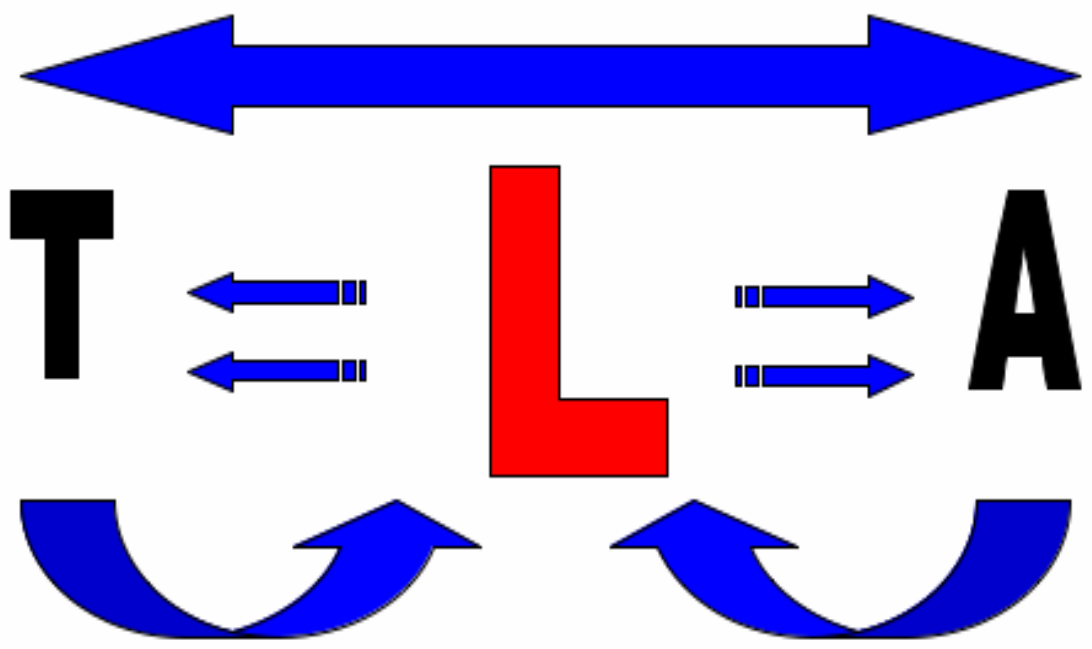

Fig. 1. TLA overview 


\section{Effective Professional Learning}

\begin{tabular}{|c|c|c|}
\hline $\begin{array}{l}7 \text { Principles of Highly Effective } \\
\text { Professional Learning }\end{array}$ & Teacher Knowledge and Skills & Effective Professional Learning Models \\
\hline Focused on student outoomes & \multirow{3}{*}{ PEDAGOGICAL KNOWLEDGE } & \multirow{7}{*}{$\begin{array}{l}\text {-Professional learning teams } \\
\text { oaction leaming } \\
\text { ostudy groups } \\
\text { ocase discussions } \\
\text {-Peer observation } \\
\text {-Mentoring } \\
\text {-Coaching } \\
\text {-In-house programs } \\
\text {-External consultant/critical friend } \\
\text {-External workshops } \\
\text {-Accredited courses } \\
\text {-Structured professional reading } \\
\text {-Personal professional reading } \\
\text {-Practicume/schol visits } \\
\text {-Online learning } \\
\text {-Professional conversations }\end{array}$} \\
\hline $\begin{array}{l}\text { Focused on and embedded in teacher } \\
\text { practice }\end{array}$ & & \\
\hline $\begin{array}{l}\text { Informed by best available research on } \\
\text { effective teaching and learning }\end{array}$ & & \\
\hline $\begin{array}{l}\text { Collaborative, involving reflection and } \\
\text { feedback }\end{array}$ & \multirow{2}{*}{ DISCIPLINE KNOWLEDGE } & \\
\hline $\begin{array}{l}\text { Evidence based and data driven to guide } \\
\text { improvement and measure impact }\end{array}$ & & \\
\hline $\begin{array}{l}\text { Ongoing, supported and fully integrated } \\
\text { into the culture and operations of the } \\
\text { system - schools, networks, regions and } \\
\text { the centre }\end{array}$ & \multirow[t]{2}{*}{$\begin{array}{l}\text { PEDAGOGICAL CONTENT } \\
\text { KNOWLEDGE }\end{array}$} & \\
\hline $\begin{array}{l}\text { An individual and collective } \\
\text { responsibility at all levels of the system }\end{array}$ & & \\
\hline
\end{tabular}

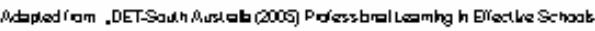

Fig. 2. 7 Principles

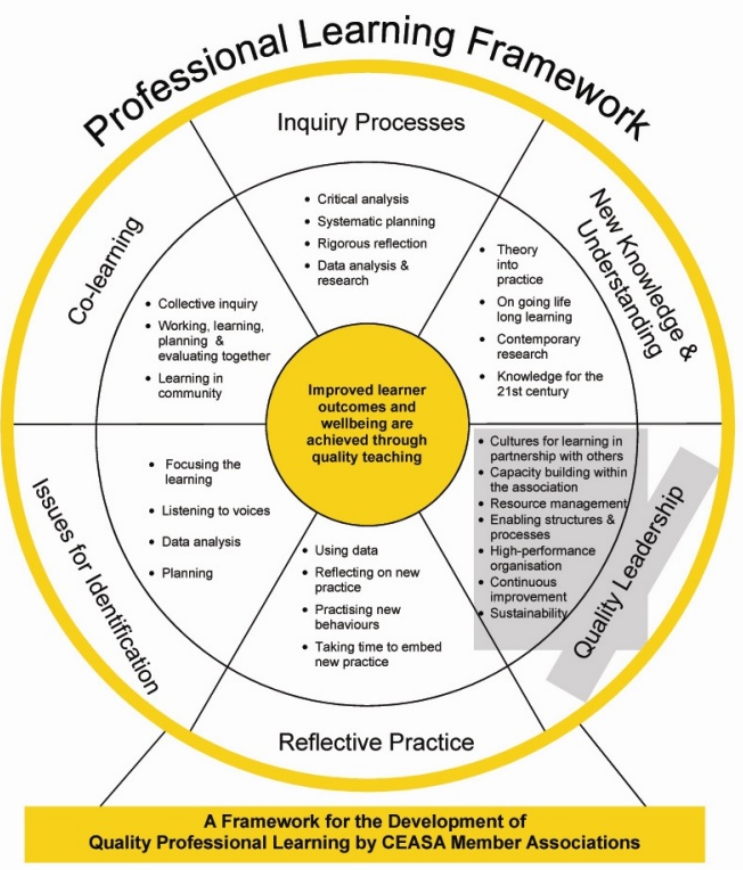

Fig. 3. Framework of Professional Learning 
design and pedagogical practices. There is no single starting point. When planning for learning using the Framework. The starting point may come from data, from an issue, from research, from a "system" requirement, or from the setting up of a professional learning community. The starting point could come from teachers or individuals analysing an element or descriptor of the Professional Standards for Teachers.

\section{Importance and Effects of Professional Learning}

The importance and effects of professional learning have focused on several areas including:

- Teachers

○ Educational goals: classrooms, students, subject area

- Transformation of teaching

○ Encouragement and support

o Improvement in student outcomes

- Four interconnected factors:

○ Student learning

- Authentic pedagogy

- Organisational capacity

○ External support

- Results

- Challenging learning experiences for all students

- A school culture that nurtures staff collaboration and decision making

○ Meaningful opportunities for professional growth

\section{Professional Learning and Professional Standards}

The initiative's 'Self-assessment Framework' articulates how schools can use their data to align teachers' individual learning needs with school priorities, goals for student learning and teacher professional learning. The accreditation process comprises five elements:

1. induction for teachers new to the school;

2. use of multiple sources of feedback on teacher effectiveness for individual teachers and teams of teachers;

3. customised individual teacher development plans based on individual development needs;

4. quality professional development to meet individual development needs; and

5. belief by teachers that the school has a performance and development culture.

\section{The Context and Using Information Technology}

McCrea (2009) identifies that “... with technology evolving at the speed of light, and everyone looking to benefit from the latest, greatest hardware and software, keeping up can be challenging for educators, administrators, and school districts themselves". 
Wenger (2001) states that “... new technologies such as the Internet have extended the reach of our interactions beyond the geographical limitations of traditional communities, but the increase in flow of information does not obviate the need for community. In fact, it expands the possibilities for community and calls for new kinds of communities based on shared practice". He believes that the concept of community of practice $(\mathrm{CoP})$ is influencing theory and practice in many domains. From humble beginnings in apprenticeship studies, the concept was grabbed by businesses interested in knowledge management and has progressively found its way into other sectors. It has now become the foundation of a perspective on knowing and learning that informs efforts to create learning systems in various sectors and at various levels of scale, from local communities, to single organisations, partnerships, cities, regions, and the entire world. Within my own current work environment the use of 'Moodle' as a learning portal has been implemented to break down the barriers of what seen to be "three campuses, but one school". In providing an online interface for the delivery of professional learning materials and updates, together with opportunities for signing up online for staff workshops. The models presented in section 2.1 have been used as a basis for the professional learning opportunities.

\title{
6 Sustainability of a PLC
}

Effective professional learning is grounded within a range of principles, processes, structures and activities that have as their focus the development of the knowledge, values, relationships and practices that will have a positive impact on the learning outcomes of all students. Sustainable professional learning and development needs to be planned. It is about the direction and implications of change and is not about the maintenance of the status quo. Teachers that make a difference are those who work together, have a sense of responsibility for their students' learning and a sense of efficacy in achieving desirable outcomes.

When designing professional learning for teachers planning needs to ensure that each of the elements is addressed and incorporated to ensure that the learning is sustainable, that pedagogical change happens and student outcomes are improved. No one element is more important than another, planning can start at any element, but all elements must be included.

\section{Lessons Learnt}

\author{
The Vision \\ - Focus on the students \\ - Set priorities \\ - $\quad$ Nurture the staff and the students $\rightarrow$ develop the community \\ - $\quad$ Engender confidence in those that you are working with and for \\ Relationships \\ - Build an atmosphere which provides a caring and productive environment \\ - Develop trust and relationships that reflect this \\ - Encourage collaboration \\ - $\quad$ Reduce isolation $\rightarrow$ bonding
}


Empowerment + ownership + opportunities

- $\quad$ Promote increase quality

- $\quad$ Set (high) expectations

Academic Focus

- Make connections

- $\quad$ Encourage professional reading; Develop a discourse

- Awareness and knowledge of purpose and philosophy (by all)

- Encourage informed decision making about adoption and implementation

- Continuous learning, continuous interactions $\rightarrow$ assimilate ideas and support

- Identify new practices $\rightarrow$ conduct action research

Feedback

- $\quad$ Should be meaningful and constructive

- $\quad$ Provide a safe forum for discussion; Reinforce the values of the community

- Develop procedures for management and the resolution of conflict; Peer mediation; Linking - identify, form $\rightarrow$ action research

\section{Leadership}

- $\quad$ Be at the centre, not the top

- Share, be available, have a physical presence (accessibility is the key)

- $\quad$ Provide opportunities for stimulating conversation about T\&L $\rightarrow$ bind ; Persistence; Role of supporter and provider of assistance

\section{Inclusivity}

- $\quad$ Provide foresight and personal involvement in nurturing the expansion process

- Fashion meaningful ways for teachers to come together to focus on issues and work that concerns all of them

- Start with those ready to start BUT note and remember it is imperative to include ALL staff in a school $\rightarrow$ avoid fragmentation

Significance Factor

- The role of the Principal or other designated leader who is best positioned to help guide toward new forms of PL $\rightarrow$ share with staff in a democratically participatory way: Leadership; Power; Authority; Decision making

\section{Building ... Reflecting ...}

"To create a professional learning community, focus on learning rather than teaching, work collaboratively, and hold yourself accountable for results".

(DuFour, 2004)

Remember four crucial questions that drive the work of those within a PLC when engaging and exploring. They are:

1. What do we want each student to learn?

2. How will we know when each student has learned it?

3. How will we respond when a student experiences difficulty in learning?

4. How will we deepen the learning for students who have already mastered the essential knowledge? 
The answer to the third question separates learning communities from traditional schools. Critical to the PLC culture is the commitment to continuous improvement. The process of reflection is also important. Hord (1997) refers to a quick-fix mentality, especially prevalent in US culture, resulted in many schools being poorly prepared for their plans for change and therefore implementing change in a superficial and less-than-high-quality way. This approach might be called the "microwave oven" theory of school improvement: pop a new program in for four minutes with a designated hero to manage it and improvement is done. What then?

\section{References}

1. DuFour, R.: What is a "Professional Learning Community"? Schools as Learning Communities 61(8), 6-11 (2004)

2. Gabelnick, F., MacGregor, J., Matthews, R.S., Smith, B.L.: Learning communities: Creating connections among students, faculty, and disciplines. In: New Directions for Teaching and Learning, vol. 41. Jossey-Bass, San Francisco (1990)

3. Hill, A Professional Learning Framework for CEASA Associations: Planning for embedded and sustainable teacher professional learning (1992), http: / /www.ceasa.asn.au/documents/funding_PLF_Background.doc

4. Hord, S.: Professional Learning Communities: Communities of Continuous Inquiry and Improvement (1997), http: / / www. sedl.org/pubs / catalog/items/cha34.html

5. McCrea, B.: 5 K-12 Technology Trends for 2010: a look at the top technology tools and trends to keep an eye on in the coming year (2009),

http: //thejournal.com/articles/2009/12/10/

5-k12-technology-trends-for-2010.aspx

6. Timperley, H., Phillips, G., Wiseman, J., Fung, I.: Shifting the Focus: Achievement Information for Professional Learning. A Summary of the Sustainability of Professional Development in Literacy: Parts 1 and 2. New Zealand Ministry of Education (2003), http: //www. educationcounts.govt.nz/publications/assessment/5747

7. Tinto, V.: Learning Communities: Building Gateways to Student Success. The National Teaching and Learning Forum 7(4) (1998),

http: / /www.postsecondaryresearch.org/i/a/document/ 5969_Poster1LC.pdf 